\title{
Complejidad-educación: un aporte para las generaciones futuras*
}

\author{
Taeli Gómez Francisco ${ }^{1}$ \\ (iD http://orcid.org/0000-0001-8081-1417 \\ Juan Rubio González ${ }^{2}$ \\ (iD http://orcid.org/0000-0001-8118-5104 \\ Universidad de Atacama, Chile
}

DOI: http://dx.doi.org/10.17081/eduhum.19.33.2653

Recibido: 26 de noviembre de 2016

Aceptado: 27 de marzo 2017

\section{Complexity-education: A contribution to future generations}

\begin{abstract}
Palabras clave:
Complejidad, Educación,

Conocimiento científico,

Generaciones futuras.
\end{abstract}

Key words: Complexity, Education,

Scientific Knowledge, Future Generations.

\begin{abstract}
Resumen
Este trabajo de reflexión teórica aborda los aportes que representan los paradigmas complejos y el pensamiento complejo, con el fin de enfrentar los desafíos que demanda la educación actual para las Generaciones Futuras como el sujeto educativo. En particular, desde un enfoque histórico-culturalista, se abordará la relación conocimiento científico-educación, para analizar lógicas educativas institucionales que han expuesto, en los últimos tiempos, los límites de los paradigmas científicos simplificadores incapaces de resolver las contradicciones y conflictos en el ámbito educativo. Se demostrará, de paso, que los cambios deben transformar fundamentos epistemológicos e imágenes de realidad que limitan los nuevos escenarios complejos y conectados en una crisis global.
\end{abstract}

\begin{abstract}
This work of theoretical reflection tackles the contributions made by complex paradigms and complex thought with the aim of facing the challenges that today's education demands for the oncoming generations as educational subjects. In particular, from a historical- cultural view, the relationship science-education is approached in order to analyze the educational logic brought by institutions that have recently presented the limits of simplified scientific paradigms unable to solve the contradictions and conflicts of education. It will be shown, by the way, that the changes must transform the epistemological foundations and images of reality, which in turn, limit the new complex scenarios connected to a global crisis.
\end{abstract}

\section{(ब) $\Theta \Theta$}

Referencia de este artículo (APA): Gómez, T. \& Rubio, J. (2017). Complejidad-educación: un aporte para las generaciones futuras. En Revista Educación y Humanismo, 19(33), 409-424. http://dx.doi.org/10.17081/eduhum.19.33.2653

* Trabajo teórico propiciado en la implementación del Programa para la Enseñanza Integral del Derecho (PEID) del Departamento de Ciencias Jurídicas de la Universidad de Atacama, Chile. Programa que se desarrolla desde el año 2014.

1. Abogada, Académica Asociada de planta y con jornada completa de la Universidad de Atacama, Región de Atacama, Chile. Doctora en Ciencias Filosóficas de la Universidad de La Habana, Cuba. Creadora y Directora del Programa para la Enseñanza Integral del Derecho (PEID) del Departamento de Ciencias Jurídicas de la Universidad de Atacama. taeli.gomez@uda.cl , taelig@yahoo.es

2. Psicólogo, Licenciado en Psicología y Diplomado en Pensamiento Complejo en la Multiversidad Mundo Real Edgar Morin, año 2015. jj.rubio.72@gmail.com 
El hombre es hombre, y el mundo es histórico-cultural, en la medida en que ambos inacabados, se encuentran en una relación permanente, en la cual el hombre, transformando al mundo, sufre los efectos de su propia transformación.

(Freire, 2004, p.87)

\section{Introducción}

Para poder pensar en transformaciones profundas, es prerrequisito admitir un diagnóstico de los límites que tienen las actuales propuestas educativas institucionales en términos de bases y fundamentos: qué enseñar-aprender, cómo y para qué son preguntas filosóficas que no pueden dejar de ser consideradas en estos espacios de reflexión.

En primer lugar, no puede faltar, en un análisis de este tipo, la relación moderna que ha existido entre ciencia y educación, pues esta no solo se ha transformado en el contenido de lo que se estudia, sino, además, ha contribuido a establecer la imagen de realidad, en la que se establece el qué conocemos, el cómo y el para qué.

Además, existe una naturalización que considera a la ciencia no como un saber históricocultural, sino como el único saber que llega a la verdad, obviamente, a través del monismo metodológico, que representa el método científico. Sin embargo, se ha ido gestando la paradoja de un conocimiento que por un lado entrega soluciones a muchos problemas de la vida, pero al mismo tiempo crea problemáticas y conflictos, hasta hoy sin solución; en un sentido ofrece prosperidad y por otro su destrucción. En efecto, cada beneficio tiene su contario: transporte/smog, mercancías/contaminación, vacuna/ enfermedad. Así, el científico se convierte, al mismo tiempo, en un juez instructor y en asesino del crimen ecológico (Garrido, 1997). Lo cual le ha ocasionado a la ciencia y su método científico perder cierto estatus cultural. No pocos son los cuestionamientos que están tras la creación de bombas atómicas y químicas, la manipulación genética de los alimentos con riesgos incalculables para la salud humana y no humana, el apoyo a la biopiratería de semillas a costa de dominación cultural, la vivisección y la tortura animal, entre algunas de las múltiples prácticas que se han desarrollado al amparo de la ciencia.

Ante tal desafío cultural y por la presión de objetos de estudios contradictorios e interconectados -incomprendidos desde algunos dogmas a priori-, este trabajo de reflexión teórica se propone vincular educación-ciencia-complejidad y su posibilidad de convivir con otros saberes, con el objetivo de hacer una revisión a los límites de la actual educación, incapaz de asumir la responsabilidad de una especie humana en peligro de extinción. A ello, entonces, se le suma demostrar, de manera particular, la posibilidad heurística y creativa que proporciona la aplicación de un paradigma complejo, aunque no se puede afirmar uno solo, pero no como un mero desafío intelectual, sino porque su aporte y consecuencias se vinculan directamente con 
la necesidad de sobrevivencia de la humanidad como especie, en tanto Generaciones Futuras, inclusivas de lo humano-no humano.

El mundo actual, a pesar de haber alcanzado logros que han beneficiado muchos aspectos de la vida humana-no humana, deviene en crisis. En este contexto, resultan pertinentes preguntas como: ¿las instituciones socio-educativas están preparadas para comprender la envergadura de los acontecimientos?, ¿es posible tener el punto de vista de las Generaciones Futuras al momento de decidir la educación que se quiere institucionalizar? Estas mínimas, pero no por ello menos profundas, interrogantes nos requieren para evaluar y proyectar las bases de una educación con miras al mañana.

A modo de resolver estas interrogantes, en este trabajo de reflexión teórica abordaremos la relación conocimiento científico-educación, desde un enfoque histórico-culturalista que proporciona dos dimensiones para el análisis: a) una histórico-cultural propiamente tal, para referirnos a una perspectiva posible, que admita al conocimiento científico como actividad creadora de conocimiento en su dimensión cultural $\mathrm{y}$, en consecuencia, inmersa en un contexto histórico consciente de sus límites. Ello, para desnaturalizar aspectos que limitan cambios profundos en educación, principalmente en la construcción histórica de una nueva subjetividad educativa, en tanto Generación Futura. Y b) una dimensión histórico-cultural y complejidad, para indagar una relación posible entre complejidad y crisis ecosocial, considerada como un estadio que contiene una crisis ecológica y ambiental. En definitiva, para asumir que la complejidad tiene una oportunidad de lograr una amplitud de perspectiva, incluso desde la emergencia de las Generaciones Futuras.

Después de esta revisión, se intentará resignificar perspectivas sobre la educación, con una orientación más integral y con mayor grado de conciencia y responsabilidad por una especie humana en peligro de extinción.

\section{Dimensión histórico-cultural propiamente} tal

El conocimiento científico no es un algo acabado y objetivo per se, sino una actividad que se da en un contexto histórico, que la portan sujetos concretos, con intereses. Esta afirmación contiene algunos elementos que se deben revisar.

\section{El conocimiento científico como actividad}

Pupo (1990) ha investigado la categoría actividad y la ha entendido como "modo de existencia de la realidad social" (p.13). Como tal, contiene las correlaciones de sujeto-objeto, ideal-material y sociedad-naturaleza. Sin embargo, además de estas relaciones concomitantes, que en general se explican a la manera de opuestos, con la creatividad de paradigmas complejos, se ha abierto un abanico de perspectivas que relaciona cada uno de estos aspectos y los amplía a nuevos niveles de análisis y síntesis. Ello se refiere a la relación sujetonaturaleza-sociedad, que ha establecido media- 
ciones a la relación del sujeto con el objeto de conocimiento. En ese sentido, Maturana y Varela (1995) afirman al sujeto cognoscente como un ser biológico y no meras máquinas receptoras objetivas que reflejan al objeto, sino por el contrario, existirían interacciones neurobiológicas que lo lenguajean. Así, dicho por alguien: "Toda reflexión trae un mundo a la mano, y, como tal, es un hacer humano por alguien en particular en un lugar particular" (Maturana \& Varela, 1995, p.13). Morin (1992), desde un pensamiento complejo, plantea al conocimiento científico como actividad (cognición) y producto de esa actividad. En ese ejercicio, también fundamenta el carácter bioantropológico de la actividad cognitiva.

Desde una Epistemología de Segundo Orden, el sujeto comienza a ser integrado en el proceso de investigación $\mathrm{y}$, en consecuencia, emerge el sistema observador en la investigación social, con lo cual "El posicionamiento no clásico reflexivista complejo supera las disyunciones sujetoobjeto, externalidad-internalidad" (Sotolongo \& Delgado, 2006, p.63), lo que elimina la rigidez unilateral de la relación epistemológica sujetoobjeto de conocimiento.

Digamos que entender al conocimiento científico como actividad, en definitiva, es un avance histórico que permite superar el carácter objetual y metafísico para hacerlo dialogante, vivo y a la vez asumir sus límites y contradicciones. Marx alertó ya en el siglo XIX, a nivel filosófico, contra un cierto materialismo que “... solo concibe las cosas, la realidad, la sensoriedad, bajo la forma de objeto o de contemplación, pero no como actividad sensorial humana, no como práctica, no de un modo subjetivo" (Marx \& Engels, 1955, p.426). A su vez, Pupo (2004) plantea que "la subjetividad humana no es excluyente en la asimilación de la realidad. Conocimiento, valor, praxis y comunicación son sus atributos cualificadores por antonomasia. Entonces, ¿por qué separarlos?” (p.8).

Entre las proyecciones científicas que estas rupturas permiten avizorar, está la superación de las nociones de objetividad y neutralidad. Al respecto, los aportes realizados desde los paradigmas complejos conceden fundamentos contra la unidirección y favorecen la recursividad de la relación sujeto-objeto de conocimiento.

El método lineal y mecanicista que pretende un acercamiento a la verdad necesaria y universal nubla la actividad científica como práctica y la reniega al punto de ocultar la vida en sus complejas dimensiones.

Una educación que pretenda incorporar un compromiso con las Generaciones Futuras desde la ciencia -como actividad histórico culturaldebe replantearse algunos supuestos que se instalaron como verdad científica absoluta, pero que aparecen como relativas $y$, por tanto, se pueden superar.

Desde la noción de un paradigma clásico, 
resulta difícil plantearse la noción de Generaciones Futuras porque estas superan dualidades, separaciones y fragmentación. La unidad de la relación pasado-presente-futuro, que las Generaciones Futuras traen consigo, desafía pensamientos atomizadores y lineales presentes en las lógicas educativas institucionales. Así, por ejemplo, se enseña de lo simple a lo complejo, pensamiento que no explica el riesgo presente en la actualidad y aleja a las Generaciones Futuras a épocas venideras que aún no existen.

La dualidad escuela y calle, adentro y afuera, desde el universo pedagógico -contenido, materias, relatos y significados-, sin un contexto situado y la incorporación de una vida que sucede del otro lado de la puerta del aula; promueve una falsa realidad sin contradicción, sin identidad unitaria como crisis global.

Para pensar en una subjetividad educativa que se eleve como actualidad-futuro, debemos develar la dualidad de sujeto cognoscente $\mathrm{y}$ cuerpo natural. En otros términos, ¿el cogito ergo sum y la res extensa corresponden a una lógica educativa aplicable a un contexto de riesgo planetario? Asimismo, ¿estudiantes y profesores dialogan solo en un ámbito cognitivo? En este mismo sentido, ¿cómo resignificarla de tal manera que su cuerpo natural no solo sea el acompañante del cogito ergo sum? ¿Será que la razón de mantener la docilidad propia de los cuerpos que permanecen sentados e inmóviles durante la jornada que se destina al proceso de enseñanza, esta dadá por la paz que requiere el sujeto pensante - cogito ergo sum?
En ese contexto, una educación para el futuro no implica sentarse a escuchar y pensar, sino a revalorar el complejo contexto de interacción social que implica uno de enseñanza-aprendizaje, donde convergen socioafectividad (Castillo, 2011), emociones, valoraciones, sentimientos y belleza, como condición para avanzar en conjunto. Toda subjetividad debe superar límites. Se debe pasar de la subjetividad individuo-átomo-cognición a la subjetividad colectiva humana-no humana, entretejida, que permita concebirse como una trama compleja, una educación para aprender a vivir en un contexto de incertidumbre; una subjetividad educativa para el sujeto Generaciones Futuras.

\section{El conocimiento científico se produce en}

\section{un contexto histórico-cultural}

La actividad productora de conocimiento científico está inserta en un contexto concreto y real. En la actualidad, el desafío de sobrevivir exige superar paradigmas científicos que dejaron su impronta como crisis ecosocial.

El conocimiento científico bajo el imperio de paradigmas mecanicistas, desde la modernidad, propició un ideal de dominación del hombre frente a la naturaleza. De ahí la relación epistemológica sujeto-objeto de conocimiento, la cual no es un invento de mentes perversas, sino que proviene de un contexto de modernas relaciones sociales productoras de mercancías. En esta misma idea, el conocimiento científico contribuyó a la configuración de una imagen de realidad que dejó a la naturaleza-máquina 
reducida a una cosa para ser manipulada y una actividad de conocimiento que se autoconcebiría como una dinámica yo-no yo.

Para lograr además este dominio, la naturaleza dejó de ser considerada valiosa en sí, pues se configuró como un objeto desprovisto de vida, valor y belleza. Capra (1992) recuerda, en este sentido, la estrategia de Galileo, que consiste no solo en describir la naturaleza matemáticamente, sino también, para que ello fuera posible, limitar a los científicos al estudio de las propiedades esenciales de los cuerpos materiales -formas, números $\mathrm{y}$ movimiento-. En consecuencia, obviar el resto de las propiedades como el color, el sonido, el sabor o el olor, las cuales pasarían a ser una proyección mental subjetiva.

Con esta tradición se elimina del conocimiento científico una interacción sujetonaturaleza que sobrepase los límites de la razón y de la matematización. Entonces, se establece una imagen de realidad que hace coherente su conocimiento científico clásico, razón por la cual no requiere de otras consideraciones: ni de la emoción, sentimiento, ni estética. En este contexto se producen no pocas disputas desde la filosofía y el arte, sin embargo, es desde el paradigma complejo que se reconoce al interior del conocimiento científico esta posibilidad y se logra una crítica interna, con esfuerzos por incorporar elementos éticos como la inclinación al homo sapiens amans que impulsa Maturana (1997) y el Instituto Matriztica que dirige, o la conciencia planetaria de Morin (1995), por nombrar algunos.

\section{Portadores del conocimiento científico}

Hace algunas décadas se ha venido superando -en términos históricos- la noción del sujeto productor como un organismo autónomo, individual, limitado a una lógica atomizada del descubridor o inventor. Las nuevas consideraciones epistemológicas han dado aceptación a otras dinámicas. Al mismo tiempo se admite la condición de portadores colectivos organizados en comunidades científicas, como se desprende de los aportes de Kuhn (2004) y/o Lakatos (1993), pero intencionados hacia el ámbito de la racionalidad (Morin, 2004). Con ello se visibiliza una fase del conocimiento científico, desarrollada en dinámicas que comprenden comunidades científicas con intereses y posiciones hegemónicas.

Lo anterior se desprende de la importancia -como objeto de estudio y reflexión-que tiene la noción de paradigma, considerado como fundamento y guía, límite y posibilidad, en suma, un importante aporte que implica la identificación de una pieza clave en la producción de conocimiento científico y que, de una u otra manera, afecta a sus portadores -los hace conservadores o críticos-. Morin (1992) sostiene que el conocimiento científico está limitado a modelos teóricos, categorías y razonamientos científicos que se vuelven dominantes al interior de las comunidades científicas y que son seguidos por estas en los momentos de su apogeo. Se podría decir que en algunas ocasiones el paradigma se vuelve un control cibernético para el mantenimiento de posiciones dominantes y los privilegios que van con ellas. Por ello, reconocer 
que el conocimiento científico tiene un portador, permite darle contexto práctico.

Otro aspecto relevante de las comunidades científicas, como sujetos portadores del conocimiento científico, está dado por su dinámica organizacional. Si bien en una época se establecieron en tantas disciplinas, como necesidad de especialización que propulsaban las fuerzas productivas. Hoy, sin embargo, han tenido que asumir dinámicas cada vez más complejas y que les demandan la necesidad de plantearse nuevos esfuerzos indagatorios de organización científica que complementen esfuerzos para la creación de conocimiento científico.

La organización disciplinar, si bien aún representa espacios insustituibles a nivel de organización del conocimiento científico por su capacidad de indagar realidades específicas, en otros casos ha perdido tal correlación por la incapacidad que conllevan los paradigmas simplistas al no ser capaces de comprender los sistemas complejos del mundo actual. Ello se da, principalmente, por no asumir los límites epistemológicos que tienen las estancadas disciplinas y que se encuentran desafiadas a dialogar hacia una multi, inter y transdisciplina. Así, por ejemplo, muchos de los problemas actuales, como las crisis económicas financieras, invitan a disciplinas diversas como la economía, ciencias políticas, matemáticas y las estadísticas.

El aporte científico-cultural que se le ha dado a la Transdisciplina, por ejemplo, no solo se refiere a cambios en la manera de producir conocimiento científico, como un ámbito relacional y encuentro de diversas metodologías, sino una posibilidad de comprenderlo como una transformación cultural de las ciencias, y que, por ende, involucra a la sociedad en su cultura. En este sentido avanza hacia la ruptura de fronteras y la creación de nuevas organizaciones del conocimiento científico, como la Biología Molecular que ha replanteado nuevas proyecciones investigativas. Pero también se debe entender como ámbito cultural, ya que no es solo una representación que se dispone teóricamente, sino que requiere de nuevas relaciones sociales, de un aprender a sentarse juntos entre comunidades científicas y científicos. En este contexto, el Club de Roma, que a fines de los años sesenta logró proponer una investigación integrada de la problemática ambiental, provocó una recursividad que regresaría hacia nuevos movimientos Transdisciplinarios. Ello estimuló la movilización social y la creación de grupos ambientalistas que provocaron cambios a nivel de la organización mundial político-jurídica, lo cual confluyó con plantear un objeto de estudio desafiante por su conexión indivisible para la organización científica, $y$, por cierto, un aporte a su cultura, que se comprendería como una Totalidad en crisis, un Problema global.

Cuando el conocimiento científico se plantea la sobrevivencia de la especie como problema científico, deviene desafío. Esta presión ha permeado en las disciplinas científicas, que han realizado una apertura disciplinar dialogante y de 
las que han surgido nuevas configuraciones como la Ecología Económica, Ecológica, Derecho Ambiental, la Bio-Geo-Física, entre otras. Al mismo tiempo, ha existido una dinámica de apertura a nuevas propuestas conceptuales que superan sus ámbitos de creación para irrumpir en otras disciplinas, como sucede con la Teoría General de Sistemas o la Teoría del Caos, que de las matemáticas pasan a ser utilizadas en otras disciplinas totalmente distintas como el Derecho. Lo anterior involucra un acercamiento no solo intelectual, sino a espacios reales de encuentro entre quienes lo desarrollan. Así, por ejemplo, es común no solo leer autopoiesis en las ciencias sociales, sino ver a sociólogos, antropólogos, pedagogos y abogados en conferencias dictadas por Maturana. Entre algunos de los efectos encontramos la aparición de un pensamiento científico-cultural que se va insertando en las dinámicas científicas.

También surge la necesidad de ir incorporando a la Transdisciplina la misión de fomentar una cultura científica que considere la inclusión de nuevas bases para el relato científico, la responsabilidad frente a la crisis planetaria, la importancia de la democratización del conocimiento científico; antecedentes que implican no solo replantear un grado de igualdad entre portadores de saberes culturales, sino, además, un resituar a la humanidad en su dimensión de especie.

En definitiva, la imposibilidad de respuesta que tiene la ciencia desde paradigmas simplistas para resolver los problemas ecosociales del mundo actual (cambio climático, daños ambientales, crisis sociales), le ha permitido a la humanidad replantearse no solo nuevos paradigmas científicos como la complejidad, sino también abrir espacios dialogantes con otros saberes que provienen de contradicciones sociales-ecosociales.

En este contexto, una educación que pretenda incorporar un compromiso con las Generaciones Futuras necesariamente debe considerar algunas premisas:

- Una educación institucional, al estar organizada con un énfasis en la cognición, valora el aprender como saber cognitivo, eliminando la riqueza de la relación educativa, corporal, natural, física, emocional, sensitiva, estética, etc., de sujetos bio-psico-sociales.

- La educación institucionalizada promueve un tipo de educación que no tiene por objeto las relaciones intersubjetivas entre la naturaleza humana-social-natural, sino relatos y contenidos, lo cual se evidencia con la importancia que el currículo le da al pasar la materia. Esta importancia disocia cuerpo-mente, humanoespecie, humano-no humano y genera un grado de alienación social que opera como catalizador de los conflictos sociales actuales.

- La educación, al disociar al humano del no humano, al humano-especie, humanohumano, promueve un ideal científico baconiano de conocer-poder. Enseñaraprender valores, ternura, estética y amor no es el actual objetivo de la educación institu- 
cionalizada, lo que se deja a espacios alternativos.

- La ciencia nos dividió la vida, el planeta, la sociedad y nuestro estar en ellos en tantas disciplinas científicas como requería el proceso productivo, llegando a un estadio de división y compartimentación tal, que se estudia la célula, la partícula, el átomo, la sociedad y la mente con profesores distintos, horas distintas y sin llegar a producir encuentros ni materiales y/o espirituales.

- La educación está atrapada por la Pedagogía como disciplina, y la mayor dificultad se encuentra en el escaso diálogo epistemológico con otras disciplinas, o de manera poco coherente, de ahí que la complejidad pudiera cumplir el rol de paradigma científicomediador.

En definitiva, la sociedad moderna, de la mano con la ciencia como un saber histórico cultural, con su particularidad de conocimiento y el reduccionismo del método científico, está limitada para comprender e interactuar bajo paradigmas mecanicistas, simplificadores $\mathrm{y}$ sobre la imagen de mundo que ha producido todo tipo de dualidades como saber científico y cotidiano, y en especial el yo-no yo, sea humano y no humano, un mí y otro, un sujeto cognoscente y objeto de conocimiento, un hoy y un futuro, en definitiva.

En este sentido, uno de los desafíos para la educación es admitir la trama de la vida, superar los reduccionismos; un saber científico que comprenda paradigmas complejos y los aportes del pensamiento complejo, como de otros que emergen de la misma necesidad de superar crisis globales, planetarias y entramadas.

El supuesto educativo, entonces, debe contener la subjetividad educativa Generación Futura que supere el ámbito de comprensión crítico-cognitiva como conciencia individual, para llegar a una conciencia social crítica de sus bases.

\section{Una dimensión histórico-cultural y} complejidad

Con esta dimensión se pretende acercar la relación complejidad y crisis ecosocial, en términos que la primera surge en el contexto de la segunda (Gómez, 2015).

El nuevo milenio no puede ocultar una crisis ecosocial intimidante e intensa, la cual obliga a asumir responsabilidades en los procesos de creación de saber científico, fundamentalmente, frente a los reduccionismos que no explican las nuevas relaciones multidireccionales, caóticas y contradictorias, que alejan de la comprensión e interacción a los portadores científicos con su ser contextuado.

Como se señaló en un comienzo, existe una relación entre conocimiento científico y crisis ecosocial, la que por lo general se entiende desde una connotación de índole sociológica y ética. Sin embargo, también es posible relacionarla a nivel de paradigmas científicos. Si entendemos que 
paradigma contiene conceptos fundamentales, categorías rectoras de inteligibilidad, y que los individuos de alguna manera conocen y piensan a la vez que actúan conforme a ellos, y que su proyección retroalimenta la imagen de realidad que una época tiene, habría que diferenciar, al menos en este nivel, qué paradigmas son los que han contribuido a una crisis ecosocial y cuáles podrían no seguir con ese rol.

Digamos, entonces, que un paradigma clásico-mecanicista, originado en los comienzos de la modernidad, adoptó una imagen de mundo que se inscribiría en la historia de las cosmovisiones como aquella que nos cosificó en una máquina compuesta de partes simples, con movimientos causales y lineales, apoyada en un ideal de racionalidad; con un sujeto separado del objeto de conocimiento y que pretende ser objetivo y neutral. Este dejó atrás todos los enfoques de inclinación holista totalizante, como los organicistas aristotélicos, míticos, religiosos y culturales acogidos por la Pachamama.

Esta cosificación posibilitó y fue coadyuvante en la reproducción ampliada del capital, el cual encuentra un límite en la recursiva relación destrucción de la naturaleza -autodestrucción de la humanidad-. Llegado el momento de reconocer a la naturaleza como una realidad inmanente a la historia y, también, considerar que la naturaleza humana está unida a la naturaleza no humana y, por lo tanto, la necesidad de superar la separación que implica la noción no-yo, otorga sustrato material para revolucionar paradigmas científicos y sus nociones de realidad.
La interrelación como emergente propiedad, a fines del siglo $\mathrm{XX}$, se la representa como posibilidad para unificar e integrar una dinámica que antes se encontraba desconectada. Así, el mecanicismo había divido la totalidad en partes, lo que negaba comprensión a la crisis ecosocial en la cual los problemas energéticos, la disminución de biodiversidad, las catástrofes ecológicas, accidentes nucleares, pobreza, etc., eran un momento de un mismo objeto de estudio o muchos relacionados. En este razonamiento se evidencia la insuficiencia de las divisiones disciplinarias para comprender que la interrelación es el punto de vista de la vida en una trama única; como lo hizo en su momento el intento de la Hipótesis Gaia o la Ecología un siglo antes.

Un paradigma mecanicista que encontró un imaginario de científico calculador, racional y matematizado, acorde con el ideal de dominador y conquistador de la naturaleza, coherente como ideología para el paradigma mecanicista, fue cuestionado por la ética ambiental, la cual propone la necesidad de cambio de un hombre homo sapiens conquistador de la tierra a un simple ciudadano de ella.

Morin, por ejemplo, en la generalidad de su obra-entendida como unidad-, devela su preocupación de componente ético por la trama de la vida. Por tal razón da coherencia a la complejidad como forma de ser de la realidad -actividad-, con un pensamiento que logre dimensionarla, de la manera más integral y dinámica posible, con la incerteza de la vida auto-eco-organizada. 
Así, el pensamiento complejo importa una forma de pensar y, a la vez, de estar en el mundo, razón por la cual la cognición y el valor están indisolublemente ligados. De ahí que uno de los temas que ha "calado hondo" en la literatura sobre la complejidad tenga que ver con la temática de la educación, no solo por el referente de los siete saberes necesarios para la educación del futuro de Morin (1999), sino por la preocupación de los niños como Generaciones Futuras.

De ahí surgen creativas propuestas como las de la Metodología Interaccional Integrativa (MII): Un modelo de aprendizaje (Ibáñez, 2005), que replantean el aula y la interacción en ella, principalmente, por la importancia de asumir las rupturas contra un paradigma científico destructor y por la oportunidad de aprender a asumir la realidad que desborda los legalismos y el orden para aceptar la incertidumbre de incorporarnos en ella, de superar los límites limitantes, que separan dicotómicamente nuestros referentes, por unos límites fundantes dinámicos hacia la interconexión, de los que habla Najmanovich (2005).

En este sentido, una lectura interrelacionada nos entrega información de las maneras de concebir la realidad, de los límites para pensarla, de las metodologías y técnicas coherentes para ella y que, por cierto, tienen el gran desafío contextual de contemplar a las generaciones futuras como sujeto-cognoscente actual.
En razón de tal contexto surgen las interrogantes: ¿cuáles son los ámbitos que se requieren transformar para plantearnos seriamente una educación que esté a la altura de los desafíos que nos depara el siglo XXI? ¿Puede tener un aporte heurístico el paradigma complejo para enfrentar la mayor de las incertidumbres: la existencia de la especie humana?

\section{Rupturas para iniciar una educación situada-responsable}

La educación institucionalizada actual representa un estadio contradictorio (Gómez, 2010), pues, por un lado, está limitada a reproducir un sistema productivo y financiero que depende en cierto sentido de ella, tanto por la capacitación que realiza para ocupar cada uno su lugar en el modo de la producción como por el beneficio directo que reporta*. Y por el otro, las contradicciones sociales y catástrofes ecológicas no verán solución en este sistema productivo y financiero, al menos no en su estado actual.

Esta es una dicotomía que provoca la interrogante del para qué de una educación. Para algunos no hay tal interrogación, pero para este trabajo, dada la incorporación de la educación al mercado, la educación ha dejado de proyectarse en pos de la trama de la vida.

Para plantearse la formación de ciudadanos planetarios como decisión de una educación para el futuro, no puede desentenderse de su perte-

\footnotetext{
En el caso de Chile, por ejemplo, la privatización y lucro de la educación -básica, media y universitaria- y el endeudamiento que el Estado asume en beneficio de la banca privada - y no distinto de otros países latinoamericanos-.
} 
nencia cultural, pues no se educa en un qué, sino también en un para qué. Y hoy, la transcendencia de este tema no puede desentenderse de lo que implica un estar en el mundo, en el sentido de que o reproduce el statuo quo o lo transforma. Por cierto, entendemos que la posibilidad de sobrevivencia del humano-no humano debe apostar a lo segundo.

De ahí, entonces, la complejidad, como paradigma científico, no solo debemos comprenderla en su perspectiva de ideas que permiten comprender e interactuar con el mundo, sino, además, en sus fuentes históricas que imperan a la comprensión entretejida, de la misma manera que sus crisis planetarias lo están (Gómez, 2010). Interactúan los científicos y los objetos de estudio en una dinámica sujeto-sujeto-objeto-objeto, en tanto que el conocimiento es un proceso que se da en interacción social, a la vez que los objetos mantienen una conexión inter-objeto.

Lo anterior implica que:

- Cualquier actividad-conocer es un ámbito de relación que se da de manera situada e histórica. En tal sentido se deben admitir estrategias didácticas complejizantes (Ruedas, 2016).

- La relación sujeto-objeto significa cogniciónvalor $\mathrm{y}$, por ende, una negación a la neutralidad y objetividad.

Los objetos están conectados $\mathrm{y}$, como relación dialéctica, no se puede simplificar su perspectiva.
- Una lógica que busca comprender el aporte de la complejidad, en la dimensión históricocultural propiamente tal, requiere resituar a la educación en este contexto.

- En los ámbitos educativos no se aprende a conocer desde el yo a un externo no-yo, sino desde un nosotros o un yo hologramático -en un sentido Moriano, que contiene el saber científico cultural presente en las metodologías, los instrumentos y en la interacción social-. En ese sentido, más que nunca se debe admitir una educación que no enseñe a un individuo a vivir, sino a una Generación Futura a sobrevivir.

- Los universos pedagógicos ideales, elaborados al margen de las contradicciones actuales por instituciones gubernamentales encargadas del currículo, limitan la posibilidad de enseñar-aprender a tener el punto de vista de la totalidad, por el contrario, separan la idea de su materialidad hasta darle autonomía, desconectan lo junto, concilian la contradicción irreconciliable y fomentan un pensamiento analítico y reduccionista de lo estético, de las emociones y valoraciones.

\section{La educación es un estar en el mundo y no un formarse para él}

A diferencia de concebir a la educación como algo que sustrae de la sociedad a personas para formarlas y posteriormente devolverlas con un plus, creemos que nunca sale y siempre está, no hay distintas sociedades. De ahí, entonces, la educación es un estar en el mundo, no un deber ser -futuro-, sino un ser -actual-, razón por la cual no se aprenden matemáticas ni ciencias sociales, sino maneras de relacionarse, de sentir, 
modelos, metodologías, imágenes con las cuales conocemos, interpretamos e interactuamos, con currículos de pertinencia cultural (Mora, 2009).

En esa lógica, se existe, como Generaciones Futuras, en un continuo indivisible temporal. En este contexto, un pensamiento complejo aporta la posibilidad de negar todo reduccionismo, como también comprender la emergencia, incertidumbre, la relación todo-parte, pasado-presentefuturo, lo local-global-todo-parte, al sujetosujeto-objeto-objeto, yo-yo no, humano-no humano.

De tal manera, las Generaciones Futuras serían un tejido que comprende al humano-no humano en un tiempo tan indivisible como histórico y, con ello, un estadio de conciencia social. Así, no puede ser relatada, debe vivirse en un aula compleja sin límites espaciales, los que son difusos complejos, que se circunscriben a la vida y no a una sala.

Entonces, pensar en una educación para esta época no es un desafío intelectual, sino un pensar desde la contradicción, solo que esta vez entre las posibilidades está la síntesis que arriesga la vida humana-no humana.

\section{Por qué pensar en las Generaciones} Futuras como sujeto educativo y en un aula compleja para él

Las Generaciones Futuras, como categoría que emerge de la práctica, se han conceptualizado como aquellas que en su proceso de existir no sacrifican a las futuras. En consecuencia, representan no solo los límites de racionalidades clásicas y paradigmas simplistas, sino también el aporte de perspectiva de los paradigmas complejos. Ella contiene la unidad del ser y no ser; los vivos y los aún no existentes; las certezasincertidumbre; lo humano y no humano; lo local y lo global o el movimiento todo-parte; lo simple y lo complejo; lo cognitivo, valorativo, estético. En otros términos, el qué enseñar, cómo enseñar y para qué es un traje que le queda grande a las respuestas dadas desde la consideración de un sujeto-estudiante del aula de un escuela, considerado de manera atomizada.

En definitiva, concebir que el sujeto educativo sean las Generaciones Futuras implica una revolución de paradigma. Hemos venido sosteniendo que para concebir lo que significa un humano se requieren términos como el de mínimo eco-social concreto, en tanto sujeto que porta un ADN, en este caso de Generaciones Futuras (Gómez, 2010), y que Morin contribuye con el Principio Hologramático de un Pensamiento Complejo (2002). Entonces la educación se debe plantear el desafío: su sujeto educativo son, ni más ni menos, las Generaciones Futuras.

El aula para este sujeto educativo debe ser un aula compleja, que dé espacio a todas estas cualidades dialécticas mencionadas en el párrafo precedente.

Las Generaciones Futuras deben aprender a sobrevivir, ese es el límite del aprendizaje actual, razón por la cual el aula no puede pensarse sin proyección espacial ni temporal.

Las ciencias no debieran ser elúnico contenido 
de la enseñanza, no se aprenden relatos sino a decirlos, a destruirlos y construirlos.

El aula es un complejo de relaciones sociales que deben acercar al humano-no humano, en tanto el aula los comprende como acontecer histórico.

El aula de las Generaciones Futuras no está en..., sino, más bien, es la propia práctica revolucionaria.

\section{A modo de reflexiones finales}

- Preparar una educación para la trascendencia de los acontecimientos actuales-futuros, debe partir del punto de vista de las Generaciones Futuras como sujetos educativos.

- Los límites de la institucionalidad educativa actual obstaculizan las necesidades de cambios educativos al no sincronizar el qué enseñar-aprender, el cómo y el para qué con la transcendencia de la incertidumbre de la vida.

- La ciencia ha contribuido a estos límites, en tanto mantiene, cultural y epistemológicamente, supuestos naturalizados hacia reduccionismos y simplificaciones tanto de los objetos de estudio y la forma en la cual se organizan las relaciones sociales educativas que los soportan.

- Existe una posibilidad heurística y creativa que proporciona la aplicación de un paradigma complejo, incluido el pensamiento complejo, en tanto permiten imbricar modelos científicos y nociones de realidad que comprenden críticamente una crisis ecosocial de manera totalizante, lo cual es un aporte en tanto dan soporte teórico a la unidad dialéctica pasadopresente-futuro, global-local, todo-parte, sujeto-objeto, teoría-práctica, cogniciónvalor-estética-emociones, en definitiva a la compleja consideración Generaciones Futuras, inclusivas de lo humano-no humano.

- Una educación preparada para las incertidumbres debe admitir la unidad de contrarios dialogantes que implica ser y no-ser. En definitiva, una educación debe asumir el desafío de la posibilidad de sobrevivir como especie humana-no humana.

\section{Referencias}

Capra, F. (1992). El punto crucial. Buenos Aires: Editorial Troquel.

Castillo, M. (2011). La socioafectividad en la educación desde la complejidad. Educación Humanismo, 13(21), 129-146. Recuperado de http://portal.unisimonbolivar.edu.co:82/rdigital/educacion/index. php/educacion

Freire, P. (2004). ¿Extensión o Comunicación? La concientización en el medio rural. México: Siglo XXI.

Garrido, F. (1997). Las ecopolíticas. Madrid: Editorial Trotta.

Gómez, T. (2010). El nuevo paradigma de la complejidad y la educación: una mirada histórica. Revista Polis, 9(25), 183-198. Recuperado de http://www.scielo.cl/pdf/ polis/v9n25/art10.pdf

Gómez, T. (2015). La crisis medioambiental y su impacto como epistemología compleja. Revista Luna Azul, 41, 254-273. Recuperado de http://www.redalyc.org/ articulo.oa? $\mathrm{id}=321739268014$ 
Ibáñez，N. (2005). Metodología Interaccional Integrativa (MII): Un modelo de aprendizaje. Revista Esquemas Pedagógicos, 6, 28-34.

Kuhn, T. (2004). La estructura de las revoluciones cientificas. México: Fondo de Cultura Económica.

Lakatos, I. (1993). La metodología de los programas de investigación cientifica. Madrid: Alianza Universidad.

Marx, C. \& Engels, F. (1955). Obras escogidas II. Moscú: Ediciones en lenguas extranjeras.

Maturana, H. (1997). La objetividad. Un argumento para obligar. Santiago de Chile: Dolmen Ediciones.

Maturana, H. \& Varela, F. (1995). El árbol del conocimiento. Santiago de Chile: Editorial Universitaria.

Mora, R. (2009). La diversidad cultural en los procesos de construcción currícular. Educación Humanismo, 16, 64-74. Recuperado de http://publicaciones.unisimonbolivar.edu.co/rdigital/ojs/index.php/ educacion/article/view/876/873

Mora, R. (2009). La diversidad cultural en los procesos de construcción curricular. Educación Humanismo, 11(16), 64-74. Recuperado de http://publicaciones.unisimonbolivar.edu.co/rdigital/ojs/index.php/ educacion/article/view/876/873

Morin, E. (1992). El Método IV. Las ideas. Madrid: Editorial Cátedra.

Morin, E. (1995). Civilizar: La nueva conciencia planetaria Tierra Patria. Recuperado de http://www.cafolis.org/ index $2 . p h p ?$ option $=$ com_content\&do_ $\mathrm{pdf}=1 \& \mathrm{id}=361$

Morin, E. (1999). Los siete saberes necesarios para la educación del futuro. París: Organización de las Naciones Unidas para la Educación, la Ciencia y la Cultura UNESCO.

Morin, E. (2002). La cabeza bien puesta: repensar la reforma, repensar el pensamiento. Buenos Aires: Nueva Visión.

Morin, E. (2004). La epistemología de la complejidad. Gazeta de Antropología, 20, 1-14. Recuperado de http://www.ugr.es/ pwlac/ G20_02Edgar_Morin.html

Najmanovich, D. (2005). Estética del pensamiento complejo. Andamios, 1(2), 19-42. Recuperado de http:// w w w. s c i e lo.org.m x/s c i e 1 o. php?script $=$ sci arttext\&pid $=\mathrm{S} 1870$ 00632005000300002\&lng=es\&tlng=es.

Pupo, R. (1990). La actividad como categoría filosófica. La Habana: Editora Ciencias Sociales, Instituto del Libro.

Pupo, R. (2004). La Filosofía y su discurso plural. En Evento sobre patrimonio inmaterial. La Habana: Del Mediterráneo, SCIF S/P.

Ruedas, M. (2016) Aportes axiológicos de experiencias didácticas complejizantes en la formación de docentes. Educación Humanismo, 18(30), 28-41.

Sotolongo, P. \& Delgado, C. (2006). La revolución contemporánea del saber y la complejidad social: Hacia unas ciencias sociales de nuevo tipo. Recuperado de http://bibliotecavirtual.clacso.org.ar/ar/ libros/campus/soto/soto.html. 